\title{
Florence Dobby-Poirson, Le pathétique dans le théâtre de Robert Garnier
}

\section{Michele Mastroianni}

\section{(2) OpenEdition}

1 Journals

\section{Edizione digitale}

URL: https://journals.openedition.org/studifrancesi/26116

DOI: 10.4000/studifrancesi.26116

ISSN: 2421-5856

\section{Editore}

Rosenberg \& Sellier

\section{Edizione cartacea}

Data di pubblicazione: 1 avril 2007

Paginazione: 162

ISSN: 0039-2944

\section{Notizia bibliografica digitale}

Michele Mastroianni, «Florence Dobby-Poirson, Le pathétique dans le théâtre de Robert Garnier», Studi Francesi [Online], 151 (LI | I) | 2007, online dal 30 novembre 2015, consultato il 22 novembre 2021. URL: http://journals.openedition.org/studifrancesi/26116; DOI: https://doi.org/10.4000/studifrancesi. 26116

Questo documento è stato generato automaticamente il 22 novembre 2021.

\section{(c) (1)}

Studi Francesi è distribuita con Licenza Creative Commons Attribuzione - Non commerciale - Non opere derivate 4.0 Internazionale. 


\title{
Florence Dobby-Poirson, Le pathétique dans le théâtre de Robert Garnier
}

\author{
Michele Mastroianni
}

\section{NOTIZIA}

FLORENCE DOBBY-POIRSON, Le pathétique dans le théâtre de Robert Garnier, Paris, Champion

(«Bibliothèque Littéraire de la Renaissance», LXVI), 2006, pp. 662.

1 La thèse dottorale di F. Dobby-Poirson arricchisce i recenti studi sul teatro del Cinquecento francese con un contributo corposo e, senza dubbio, importante, che sceglie l'angolatura del pathétique come categoria interpretativa - e riassuntiva - del 'tragico' di Garnier. Ma nel momento in cui l'A. si concentra su tale nozione sulla scorta di una vulgata manualistica, intende anzitutto precisarne il senso a partire da una disamina storica che evidenzi sia l'evoluzione del concetto sia le differenti modalità del ricorso all'emozione, in particolare nell'impiego della retorica nel contesto del teatro tragico. Dopo avere ricostruito in modo sintetico ma accurato il discorso classico (aristotelico in particolare) e patristico concernente il patetico inteso come capacità di commuovere, l'A. sottolinea i vari approcci al concetto nel Cinquecento, epoca in cui rigorosamente si fa slittare l'espressione delle passioni (espressione in cui consisterebbe, appunto, l'essenza del patetico) dal campo dell'eloquenza a quello del teatro («Les passions, qui ne peuvent s'exprimer dans l'éloquence, trouvent sur la scène un espace de liberté où elles peuvent troubler les âmes sans nuire à l'ordre public», $\mathrm{p}$. 72). Una rapida analisi dei commenti cinquecenteschi alla poetica di Aristotele soprattutto di quelli italiani che hanno influenzato l'art tragique francese - e la rassegna degli arts poétiques e delle molteplici teorizzazioni della tragedia in Francia (quali compaiono in veri e propri trattati, ma anche in pièces liminaires di vario genere) rende manifesto il ruolo del movere - del mouvoir les affects - all'interno del genere tragico. Al termine di un processo pluridecennale di riflessione critica Vauquelin riassume - 
influenzato, secondo l'A., dall'opera teatrale di Garnier - le considerazioni cinquecentesche sul patetico, sottolineando come tale 'patetico' non sia «necessariamente legato a uno scioglimento infelice della vicenda» e come «il piacere supremo sia provocato dallo spettacolo dei sentimenti contrari che si succedono nei personaggi e fanno passare lo spettatore dalla compassione al sollievo» (p. 84). Prima di Vauquelin, La Taille nel suo Art de la tragédie, superando il dibattito d'origine patristica - ripreso dall'umanesimo cristiano -, aveva finito "per identificare il patetico per quello che esso era realmente nella tragedia umanista: un principio di piacere, di cui il docere era forse soltanto l'alibi» (p. 95).

2 Stabilita, pertanto, la centralità della nozione di patetico nell'elaborazione di una poetica della tragedia, F. Dobby-Poirson analizza l'opera di Garnier - senza dubbio l'autore drammatico di maggior rilievo nel Cinquecento francese, e in quanto tale esemplare di tutta la produzione teatrale rinascimentale - nella prospettiva specifica della produzione dell'emozione, dimostrando come in questo autore il 'patetico' concerna non solo l'espressione delle passioni da parte dei personaggi ma anche la drammaturgia stessa, nei suoi aspetti strutturali e retorici. Vengono così individuati $\mathrm{i}$ temi e gli argomenti di predilezione, fra cui spicca la tematica troiana, con Troia figure emblématique du malheur, la cui simbolica diventa schema espressivo per la produzione tragica di Garnier (si consideri l'indubbio rapporto fra La Troade e Les Juifves, già ben studiato da Sabine Lardon). Sempre nella prospettiva del patetico è analizzata la costruzione drammaturgica, dalla funzione dei luoghi alla strutturazione delle situazioni tragiche alla rilevanza che assume l'estensione temporale al modo in cui vengono delineati i personaggi. Infine, viene studiata l'expression pathétique attraverso una minuziosa disamina del linguaggio, distinguendo il linguaggio delle varie categorie attoriali e repertoriando metafore e simboli. Se un appunto si può muovere a questa vasta rassegna è che, forse, sarebbe stato opportuno sottolineare con maggior forza come la precipuità 'patetica' del linguaggio di Garnier sia connessa più agli influssi dei modelli drammatici (Seneca) e linguistici (petrarchismo, novellistica) che a un puro e semplice sforzo di incarnare in modo nuovo le teorie di matrice aristotelica e oraziana. Si tratta comunque di un lavoro ricco e denso di materiale, utile allo studioso del tragico cinquecentesco. 